\title{
CARTAZES NA CONTRAMÃO: CONTESTAÇÃO POLÍTICA NA PAISAGEM URBANA
}

Kando Fukushima

UTFPR

kandof@gmail.com

Marilda Lopes Pinheiro Queluz

UTFPR

pqueluz@gmail.com

Resumo: O presente artigo procura refletir sobre uma pequena amostra de cartazes políticos produzidos e afixados nas cidades de Curitiba-PR e São Paulo-SP entre os anos de 2015 e início de 2016. Tratam-se de cartazes distribuídos em suportes irregulares, não institucionalizados, nas regiões centrais dessas cidades. Foram escolhidos exemplos que exploram temas diversos, como aqueles relacionados à questão de gênero, à violência racial e à corrupção na política tradicional. A seleção busca evidenciar a diversidade de possibilidades quanto à linguagem visual, os interesses sociais e a relação de autoria com os seus produtores. Pretende-se discutir brevemente a relevância desse tipo de artefato gráfico no contexto atual como produção simbólica e sua relação com o espaço urbano e o design.

Palavras-chave: Cartaz; Movimentos sociais, Paisagem urbana.

\begin{abstract}
The present paper takes into consideration a small sample of political posters produced by and found in the cities of Curitiba - Parana State and São Paulo - São Paulo State during the year of 2015 and the beginning of 2016. These posters are fixed in irregular, non-institutional places, in the central regions of the above mentioned cities. The posters chosen explore several themes such as the ones related to gender issues, racial violence, traditional politics corruption. They were selected with the purpose of demonstrating the diversity and possibilities with regard to the visual aspect, the social interests and the relationship of authorship and their producers. Its purpose is to discuss briefly the importance of this graphic instrument in the present social context as a symbolic production and its relationship with the urban space and design.
\end{abstract}

Keywords: Poster; Social movements; Urban landscape. 


\section{INTRODUÇÃO}

Em meio à complexidade que constitui as grandes metrópoles, percebemos que as relações entre a arquitetura, o sistema de transporte, a comunicação visual, a presença da natureza e das pessoas, produzem uma paisagem urbana rica em elementos que evidenciam, dentre muitas possibilidades, as tensões sociais e contradições do dia-a-dia.

Materializada de diversas formas, nem sempre percebidas, os artefatos e seus usos fazem parte da configuração do cotidiano. Este é sempre mutável, num constante processo de apropriação e negociação.

A associação entre os movimentos sociais e o design já apresentou, por diversas vezes, em suas narrativas históricas canônicas o uso dos cartazes como suporte privilegiado dessa relação (BARNICOAT, 1972; HOLLIS, 2001; MEGGS, 2009).

Para John Barnicoat (1972) um tipo específico de cartazes políticos ou "cartazes ideológicos" já se constituem como "gênero" desde 1919. Mesmo sendo possível encontrar exemplos esporádicos anteriores, o autor se refere à especificidade dessa produção baseada nos exemplos dos cartazes russos daquele período, com características que se diferenciam do que comumente chamamos de "propaganda".

Tal diferenciação não se caracteriza por um estilo visual ou técnica de impressão, mas sim pelo processo de produção coletiva. Esse aspecto é recorrente em diversos outros momentos históricos importantes desde então. Citando os mais conhecidos, apontados pelo autor, podemos mencionar a produção de cartazes na Guerra Civil Espanhola, na revolução Cubana, no Atelier Populaire de maio de 68, nos movimentos contra a Guerra do Vietnã.

Ao se referir ao Atelier Populaire, McQuinston (1993, p.54-55) destaca a experiência de produzir materiais gráficos de forma conjunta entre trabalhadores e estudantes e a urgência com que eram desenvolvidos. Mobilizadas por causas em comum (uma nova perspectiva na educação, condições melhores de trabalho, etc.), a produção desse grupo tornou-se referência importante no que diz respeito às suas soluções visuais, além da discussão promovida pelas técnicas de criação através da ação direta.

O fator do uso, processo social e produção ganham a atenção do autores, que reconhecem nas condições históricas aspectos fundamentais para o design e sua linguagem gráfica (McQUINSTON, 1993, 2004; 2015; BARNICOAT, 1972).

Mesmo diante de uma série de novos recursos informacionais, tais como os encontrados nos "meios digitais", ainda é frequente o uso do ambiente urbano como espaço fundamental de trocas de informações, publicidade e também de contestação social, prática que se confunde com as origens da própria ideia de cidade.

O espaço regulamentado para a colocação dos cartazes nas cidades onde os exemplos desse trabalho foram retirados (São Paulo-SP e Curitiba-PR) são bastante restritos. Institucionalmente, os suportes para mídias impressas nesses centros urbanos são geralmente limitados aos usos pela publicidade, normalmente de grandes empresas, e pela propaganda de Estado. Podemos citar como exemplo, os espaços específicos encontrados no mobiliário urbano administrados por empresas como Clear Channel e JCDecaux através de contratos com as prefeituras. A poluição visual é de fato um problema que interfere profundamente na paisagem urbana e a regulamentação da comunicação em vias públicas já vem sendo discutida há muito 
tempo ${ }^{1}$. O excesso de outdoors e fachadas com marcas luminosas enormes são exemplos de artefatos que foram regulamentados e aparentemente ajudaram a estabelecer um ordenamento visual melhorado nos centros urbanos. Mas junto com as melhorias foram estabelecidas também novas maneiras de explorar comercialmente o espaço público, cujo resultado é ainda mais restritivo e centralizador no que diz respeito aos interesses sociais amplos.

Para utilizarmos esses espaços de forma regular, são necessários grandes investimentos financeiros ${ }^{2}$, que na prática excluem uma grande parcela de possibilidades de usos da comunicação visual na cidade. Justifica-se, parcialmente, tais regulamentações por noções de racionalização e ordem, ligadas ao combate à poluição visual.

Neste contexto, uma vez que os exemplos nesse artigo utilizam espaços irregulares, a própria colocação dos pequenos cartazes são práticas que contestam essas regulações, expondo outras possibilidades de usos desse tipo de material impresso e evidenciando temáticas sociais urgentes, presentes no espaço e no tempo daqueles que circulam pelas ruas da cidade.

Além das grandes peças publicitárias institucionalizadas, esses pequenos impressos disputam a paisagem com outras manifestações visuais elencadas como "vandalismo", tais como as pichações e grafites, que também fazem parte dos processos de constituição social e simbólica da sociedade, das práticas que se articulam com o sentimento de pertencimento à cidade.

Para Massimo Canevacci (2004), a observação e a interação com a cidade é constituída pelo olhar crítico, "multiperspectiva", que possui uma dinâmica ao mesmo tempo voltada para dentro e para fora:

O olhar do observador metropolitano é, de fato, reflexivo e, portanto, não apenas participante (conforme a clássica colocação etnográfica de observação participante), mas mais participante: a observação observante implica dirigir o olhar tanto para o interior do sujeito inserido nos fluxos da metrópole comunicacional, quanto para o exterior dele. Isso testemunha o método da comunicação visual como fazer-se ver, envolvendo seja as novas sensibilidades visuais, perceptivas, oculares, seja as informacionais, tecnológicas. (...) (CANEVACCI, 2004, p.121).

A relação do transeunte com a cidade pode ser entendida como atividade significativa, sendo suas bases partilhadas socialmente (interesses, regulamentações, etc.). Nesse sentido, podemos considerar que a prática do design também compartilha essas associações. Segundo Victor Margolin (2000, p.60), "o design como atividade ocorre dentro de um espaço social, e sua contingência particular é definida pelos valores e limites que norteiam um determinado projeto".

Quando estabelecemos as relações das necessidades com os recursos disponíveis, elas são fundadas em valores, linguagem, hábitos, todas dimensões de

\footnotetext{
Como referencia histórica da regulamentação da publicidade externa em cidades brasileiras,
podemos citar o Ato 6, de 26 de março de 1896, de São Paulo, "que concedia permissão ao Doutor João Chaves Ribeiro para explorar seu sistema de anúncios por meio de placas metálicas colocadas nas esquinas das ruas, praças e muros da cidade." (MENDES, 2011).
}

2 Segundo tabela da empresa Clear Channel, em 2016 o custo da mídia por uma semana em 200 faces (quantidade mínima), era de $\mathrm{R} \$$ 162.500,00, sem incluir o custo de produção/impressão (CLEARCHANNEL, 2016). 
natureza social, mesmo quando estamos reinterpretando ou rejeitando algo (SLATER, 2001). É nessa relação que se entende que a investigação dos artefatos gráficos são também espaços próprios da reflexão sobre as mediações sociais e culturais.

\section{DESENVOLVIMENTO}

Diante do desafio de se criar tipologias e categorizações dos exemplos que ilustram esse trabalho, optou-se por realizar uma análise focada nas questões culturais dos artefatos, levando-se em conta alguns dos aspectos formais, como, por exemplo, as características plásticas das imagens. Para este artigo, a escolha priorizou a diversidade de temas abordados, sem o intuito de verificar a multiplicidade de manifestações sobre um mesmo assunto, visando reforçar a ideia de que este meio é usado por grupos sociais distintos, de interesses variados.

Todas as imagens são registros fotográficos realizados durante o ano de 2015 e 2016 nas cidades de Curitiba-PR e São Paulo-SP e constituem parte do trabalho de uma pesquisa que envolve as relações entre design e espaço urbano. A amostra a seguir foi selecionada com o intuito de evidenciar possibilidades e usos do espaço urbano para além dos interesses hegemônicos, utilizando o mobiliário urbano ou as paredes de forma irregular, ou seja, em lugares onde originalmente não se previa a colocação de cartazes .

Os cinco exemplos escolhidos englobam estratégias diferentes de linguagens e temáticas: conteúdo informativos, similar ao que chamamos de utilidade pública; expressões de protesto e contestação. Tais usos, de fato, são recorrentes e podem ser encontrados nos mais diversos contextos e, particularmente nessa amostra, a questão política é bastante evidente. Além disso, com exceção do último exemplo, os impressos são cartazetes, impressos em sua maioria no formato A4.

\subsection{Pirâmide social}

Alguns cartazes apresentam temas de forma muito generalizada que, embora mostrem claramente um viés ideológico, não são assinados, nem parecem estabelecer alguma relação com um evento específico.

A figura 1 indica uma pirâmide social bastante esquematizada, similar às que são utilizados em aulas de história ou geografia quando se pretende simplificar a estratificação social predominante de um determinado período, lugar ou estrutura de poder. O infográfico nos remete aos materiais didáticos, normalmente voltados ao ensino fundamental, mas não restritos a ele. Trata-se da apropriação de um recurso de visualização rápida e de fácil memorização.

A pirâmide é ilustrada com pictogramas que representam a estratificação social, ao lado de um termo definidor de cada categoria. No topo da pirâmide vemos o desenho de uma sacola de dinheiro, identificada por um cifrão, ao lado da palavra "Deus". Seguem-se os pictogramas que se referem aos "governantes", "clero", "militares", "burguesia" e, finalmente, "proletário" na base da pirâmide. 


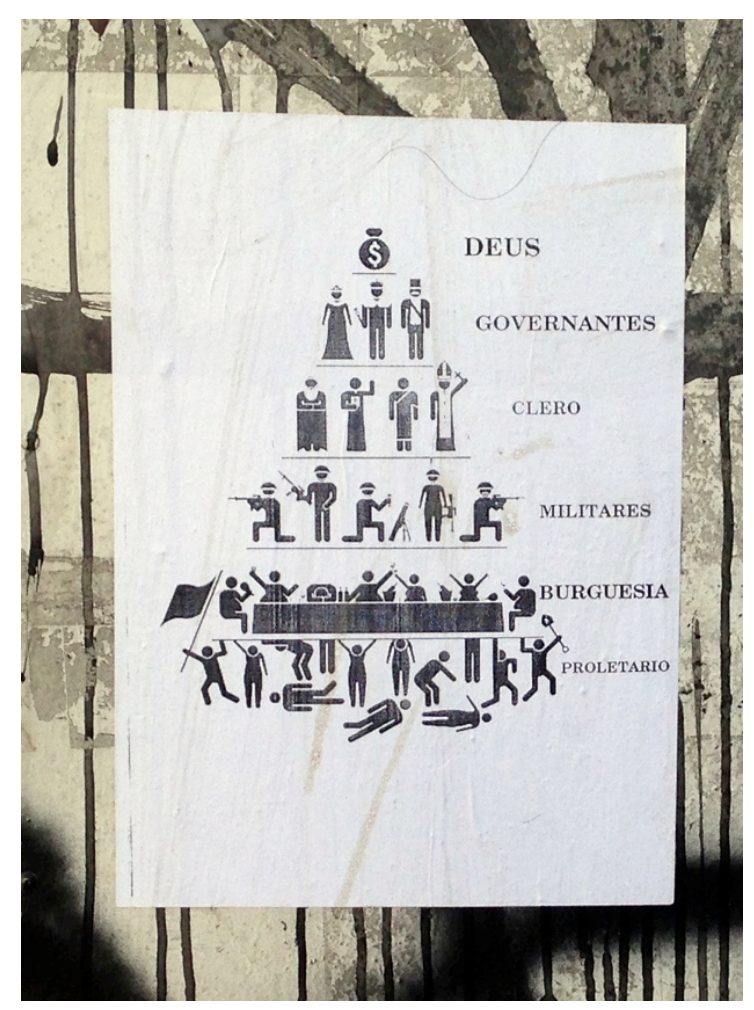

Figura 1 - Cartaz "Pirâmide social" colado nos arredores da praça Oswaldo Cruz em Curitiba.

Fonte: Foto do autor, 2015.

Ao ser colado na parede de uma banca de jornal próximo à praça Oswaldo Cruz, no centro de Curitiba, que possui uma área esportiva com grande circulação de jovens e que fica ao lado de um shopping center, o esquematismo do diagrama no local onde foi colocado sugere um tom irreverente, mesmo que não necessariamente proposital. $\mathrm{O}$ tom bem humorado pode ser verificado pelas poses das figuras: a burguesia brinda com taças num banquete, enquanto alguns proletários sucumbem ao peso da estrutura. Esta peça ganha novas dimensões de signifcado na interação com os efeitos e a gestualidade da pichação no mesmo suporte, marcas de outras formas de apropriação não institucionalizadas desses espaços.

\subsection{Gênero}

Dentre as problemáticas sociais abordadas pelos cartazes encontrados na pesquisa, um tema bastante recorrente é aquele relacionado com questões de gênero. O exemplo da figura 2 foi registrado em 2016, na Avenida Paulista, em São Paulo. Faz parte de um projeto específico chamado \#FridaFeminista e, dentre a pequena amostra apresentada neste artigo, é o único assinado por um estúdio e não por uma entidade social ou simplesmente anônimo.

Neste caso, embora aborde uma perspectiva relacionada às mulheres, o texto e a própria imagem não nos remetem a uma linguagem gráfica associada a um enfoque combativo ou de contestação muito evidente. Trata-se, afinal, de uma questão política, mas no interior das relações íntimas, pessoais. A tipografia é caligráfica e o texto escrito com grande espaçamento entre linhas, preenchendo grande parte do espaço compositivo. 


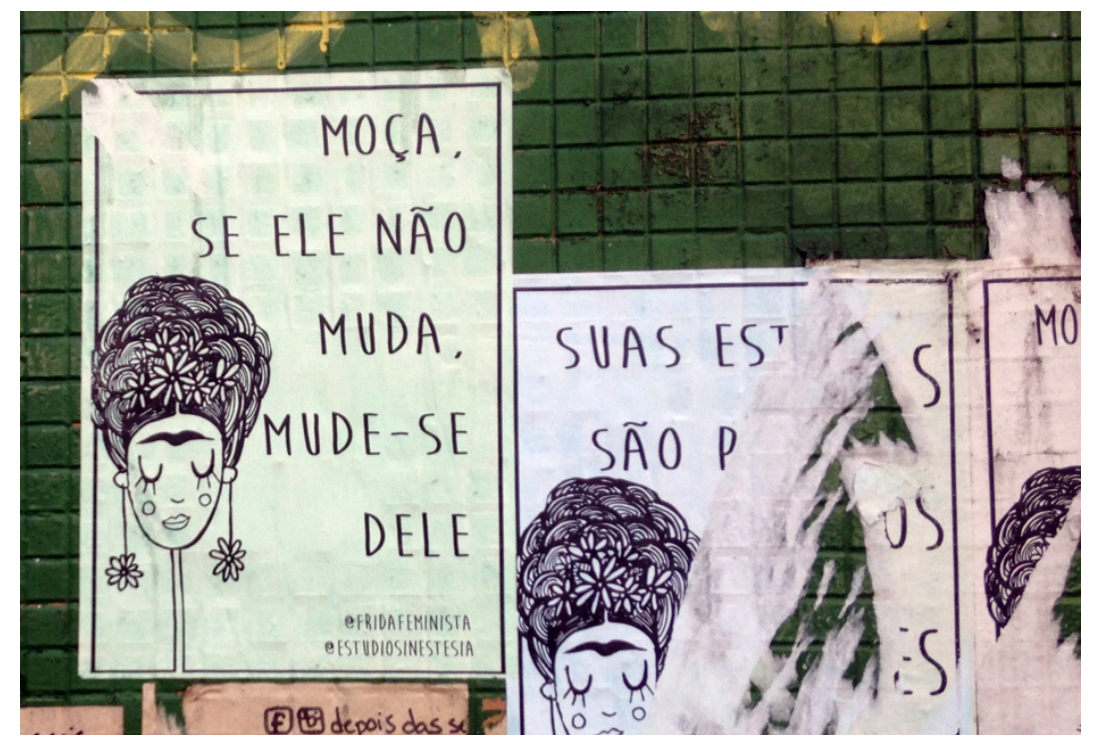

Figura 2 - Cartaz "Moça se ele não muda, mude-se dele" colado na Avenida Paulista em São Paulo. Fonte: Foto do autor, 2016.

O projeto consiste em colar cartazes pela cidade com frases relacionadas à perspectiva feminina, sempre com um desenho estilizado de Frida Kahlo, como se esta estivesse dando uma dica para quem observa o cartaz, particularmente para as mulheres. Neste exemplo, a interação entre as mídias eletrônicas e a produção espalhada pelas ruas são estimuladas pela criadora do projeto, Lela Brandão. Ela sugere na página eletrônica do projeto que as pessoas coloquem fotos dos cartazes nas mídias sociais ou mandem sugestões de frases. Desse modo, provoca-se uma rede de circulação e produção coletiva de pensamentos e de visualidades.

\subsection{Raça e violência}

A figura 3 possui um conteúdo informativo bastante objetivo. O registro do cartaz, feito no início de 2016 na Avenida Rebouças, em São Paulo, denuncia, ou no mínimo nos faz relembrar, questões graves do cotidiano.

A foto de um menino, Eduardo de Jesus Ferreira, é colocada em destaque na composição do cartaz. À primeira vista parece com os cartazes que mostram retratos de desaparecidos: não parece ser uma foto produzida num estúdio fotográfico, nem mostra a criança sorrindo alegremente na promoção de algum produto.

Lemos logo abaixo que se trata de um menino que foi assassinado numa ação da Unidade de Policia Pacificadora (UPP) na cidade de Rio de Janeiro-RJ, em 02 de abril de 2015. A informação em si, mesmo que veiculada anteriormente nos meios de comunicação tradicionais, é facilmente esquecida diante da rotina de notícias, cuja ênfase nem sempre representa os interesses dos envolvidos. Nesse caso, o cartaz é assinado pelo Projeto111, de ativistas que discutem e combatem a discriminação racial, particularmente a violência contra os negros no Brasil. 


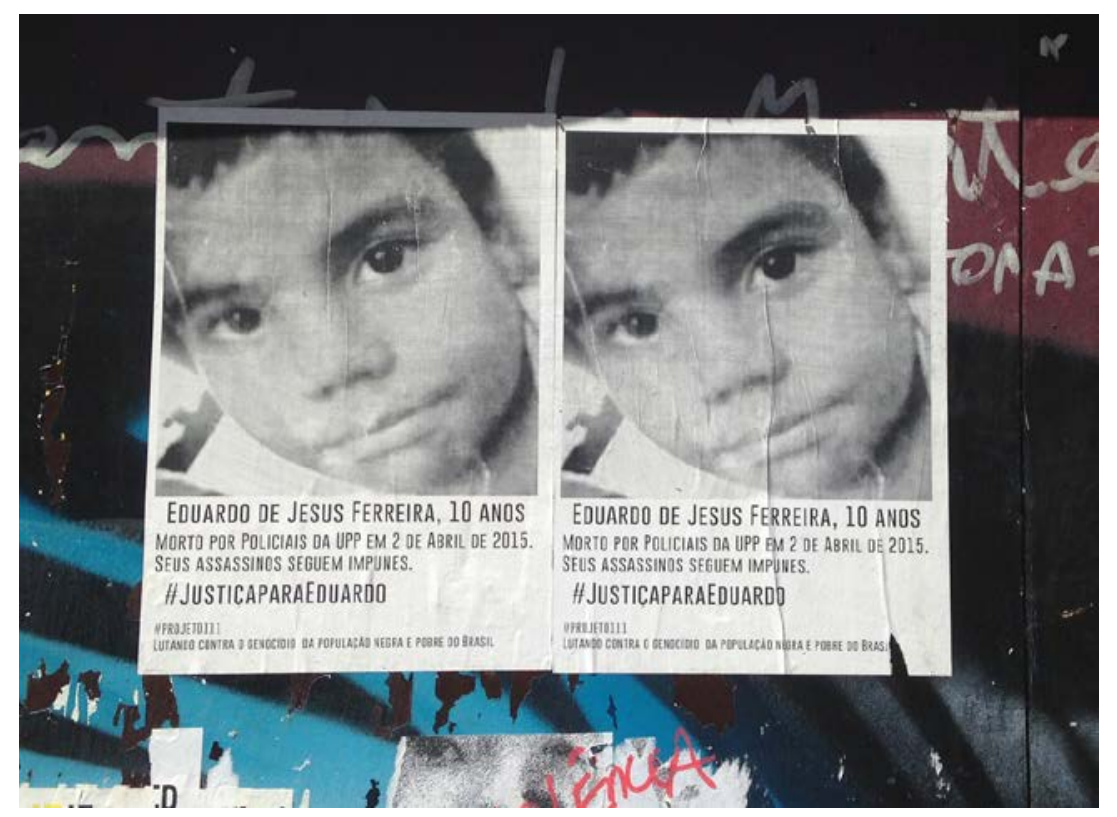

Figura 3 - Cartaz "Eduardo de Jesus Ferreira, 10 anos" colado na Avenida Rebouças, São Paulo. Fonte: Foto do autor, 2016.

A questão de classe também é colocada textualmente: trata-se uma criança pobre, em condições econômicas precárias. Ainda que a visibilidade de um crime como este não seja comparável à popularidade de notícias que envolvam temas esportivos, celebridades, tragédias naturais ou disputas políticas nacionais, o assunto é em si abrangente: é um estímulo à reflexão ligada à violência, ao papel da "segurança pública", das questões raciais e de classe. Próximo a um ponto de ônibus, relembra-se todos os dias, ou até o cartaz ser arrancado, um evento brutal, próximo ao cotidiano de milhões de pessoas em grandes centros urbanos. É importante pensar nas significações dos vários elementos gráficos do entorno e nas construções de sentidos que se somam às intervenções deste fragmento urbano.

\subsection{Estado de exceção}

Em Curitiba, o dia 29 de abril de 2015 foi marcado pelo confronto entre manifestantes, formado principalmente por professores grevistas e policiais militares em frente à Assembleia Legislativa do Paraná. A mobilização estava relacionada com a crise política no governo do Estado do Paraná, baseada em diversas denúncias de corrupção, grandes aumentos de impostos, usos indevidos de fundos previdenciários e cortes de benefícios do funcionalismo público estadual. A ação policial durante aquele estado de exceção envolveu o lançamento de bombas de gás lacrimogêneo e de efeito moral com o uso de um helicóptero, balas de borracha, cães e cassetetes. 0 embate resultou em mais de 200 pessoas feridas dentre os que protestavam.

A figura 04 mostra um exemplo de impresso que foi colado durante as manifestações posteriores ao dia 29 de abril de 2015 em Curitiba. A foto foi tirada na Avenida Cândido de Abreu, no Centro Cívico, local dos acontecimentos desta data. 


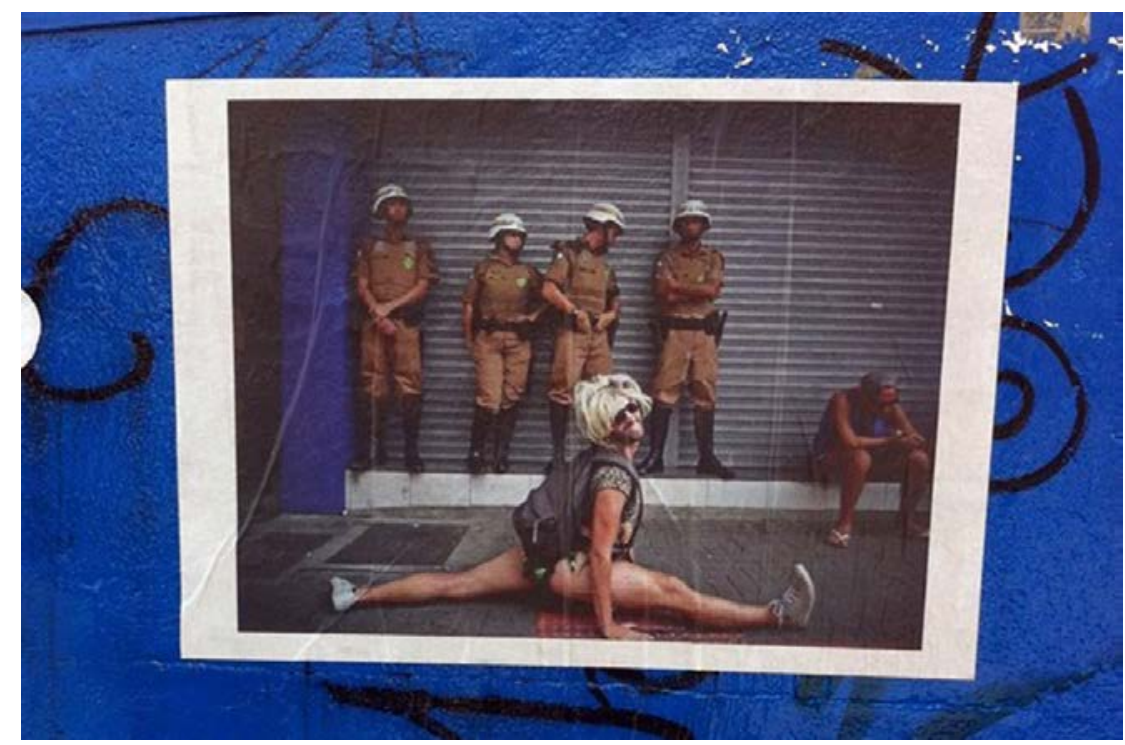

Figura 4 - Cartaz "Neide no Carnaval" colado na Avenida Cândido de Abreu, em Curitiba. Fonte: Foto de Paulo Roberto de Oliveira Reis, 2015.

Ainda que nesse período fosse possível encontrar outros cartazes que abordavam o tema de forma mais direta, com fotos da manifestação, imagens do governador e textos que aludiam ao acontecimento, optou-se por apresentar um exemplo que ilustra a diversidade de linguagens visuais e abordagens críticas que podemos encontrar nas ruas.

A foto utilizada no cartaz foi originalmente tirada durante o carnaval do mesmo ano, meses antes, onde um sorridente folião com peruca loira, a performer Neide Marela, faz um espacate diante de quatro policiais militares, uma provocação. Aparentemente constrangidos, os policiais desviam o olhar. Na foto também podemos ver um homem cabisbaixo sentado no chão, alheio ao seu entorno. Esta imagem, depois dos confrontos de 29 de abril, ganhou outras conotações de critica e ironia ao papel da polícia, a serviço do Estado e não da população.

\subsection{Cartaz político "tradicional"}

Finalmente, apresenta-se um cartaz contestatório mais típico. Aqui a mensagem não recorre a interpretações ambíguas, privilegia um único significado. Ainda que não seja particularmente memorável em sua solução visual, principalmente por não utilizar uma imagem em destaque, seu texto em letras garrafais se espalham por grande parte do impresso e são bastante diretos em seu conteúdo, como uma manchete de jornal.

A foto da figura 5 foi tirada na Avenida Ipiranga, nos arredores da praça da República em São Paulo. Nele lemos em destaque "Governo Tucano rouba merenda das crianças. É crime! CPI já!" A reinvindicação de abertura de CPI foi pautada pelas denúncias do envolvimento de diversos políticos ligados ao Governo de Geraldo Alckmin (PSDB) em São Paulo, investigados pela Operação Alba Branca. As acusações indicam pagamentos de propinas com as empresas fornecedoras e grampos telefônicos comprometedores. Tal situação afeta a distribuição de merenda escolar em pelo menos 22 munícipios de São Paulo nos últimos 5 anos. 


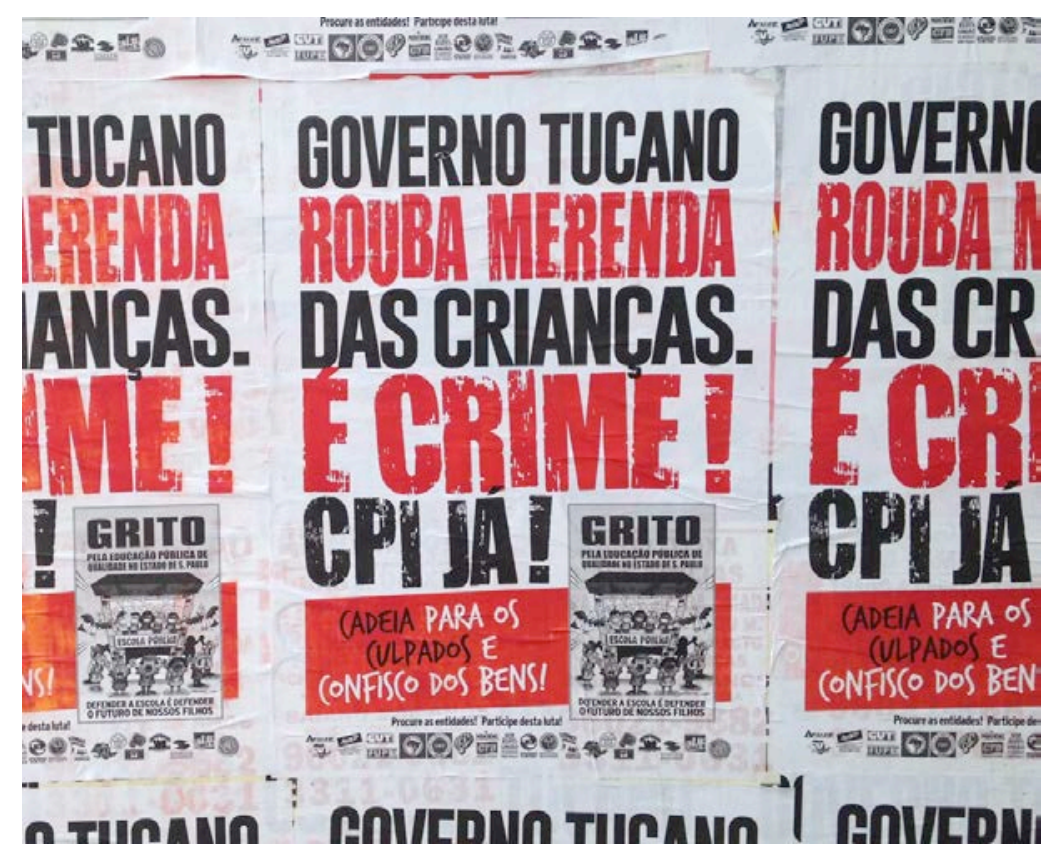

Figura 5 - Cartaz "Governo Tucano rouba merenda das crianças" na Avenida Ipiranga em São Paulo. Fonte: Foto do autor, 2016.

Existe, porém, uma peculiaridade a se destacar na composição, uma vez que no canto inferior direito existe uma segunda mensagem, esta mais abrangente, sobre a educação pública. Nela lemos : "Grito pela educação pública no Estado de São Paulo. Defender a escola é defender o futuro de nossos filhos". Nesse segundo nível de leitura, associa-se a pauta pela CPI das merendas com um conjunto de outras ações ligadas à educação pública no estado de São Paulo. Este contexto recentemente envolveu ocupações em escolas para evitar o fechamento de algumas unidades, greves de professores e outras pautas correlatas.

Assinam o cartaz uma série de entidades ligadas à educação tais como associações e sindicatos. Assim, pode se dizer que, além da linguagem visual mais tradicional do cartaz, seus promotores também estão ligados com movimentos sociais organizados, já estabelecidos, num contexto de pauta política mais típica.

\section{CONCLUSÃO}

Discutir os usos do espaço urbano, dos artefatos relacionados mais diretamente com o Design Gráfico, tais como os cartazes, permite dar visibilidade e refletir criticamente sobre as práticas do design e explorar questões de interesse social. Os exemplos utilizam processos, técnicas e estratégias à margem dos espaços institucionalizados, evidenciando algumas das demandas políticas e culturais da sociedade.

Constituindo a própria paisagem urbana, espalhados em trajetos improváveis e surpreendentes, os cartazes são artefatos constantes em nosso cotidiano, mesmo que nem sempre prestemos atenção. Destaca-se que os exemplos aqui presentes costumam ser negligenciados, pois normalmente são pequenos, alguns colocados em lugares inapropriados, com soluções visuais muitas vezes estranhas ao olhar do design dito profissional, de produção caseira, menos "vistosos" que os utilizados pela publicidade. 
Além disso, verificamos que cada vez mais existe uma ênfase nos usos dos meios eletrônicos, como as redes sociais digitais, como elemento fundamental nas discussões sobre design, cultura e sociedade. A relação entre os meios digitais e os movimentos sociais é problematizado por McQuinston (2015, p.30), onde constata que em última instância a coragem dos cidadãos e os protestos nas ruas é que são as principais forças para as mudanças na sociedade.

Assim como no caso dos cartazes, os meios digitais possuem um impacto social difícil de dimensionar e avaliar, ainda que possua alguns indicadores quantitativos mais claros (ex: número de compartilhamentos de uma postagem numa rede social). De fato, os meios digitais complementam e expandem as práticas de afixação de cartazes do tipo discutido nesse trabalho, seja porque muitas vezes são produzidos nesses meios e se beneficiam das possibilidades de distribuição de arquivos para impressão, seja pela própria ampliação das discussões e temas veiculados nas ruas.

O design investigado como uma forma de comunicação crítica pode evidenciar metodologias de projeto pouco exploradas e permite a investigação de novas soluções de produção e linguagem.

O tempo de permanência deste tipo de material impresso, diferentemente da regularidade dos materiais institucionalizados que possuem normalmente contratos de duas em duas semanas, é bastante variável. Alguns ficam apenas alguns minutos, quando retirados logo em seguida por pessoas contrárias ao conteúdo do cartaz. Outros podem permanecer por mais de um ano, normalmente quando colocados em locais de pouca circulação ou visibilidade, ou quando simplesmente não provocam uma reação contrária imediata. Evidenciam uma outra lógica de tempo e uso da comunicação visual nas cidades.

Mesmo reconhecendo a importância da organização desses ambientes públicos e a discussão a respeito da poluição visual, entende-se que as propostas referentes a esse assunto devam privilegiar seu uso democrático e que respeite a diversidade de interesses públicos. Diante deste quadro, é notável perceber que para além das tentativas de normatização restritivas, a cidade é ainda muito rica em manifestações visuais contestatórias, que representam uma das muitas faces contemporâneas da produção de design.

\section{REFERÊNCIAS}

BARNICOAT, John. Los carteles. Su historia e lenguaje. Barcelona: Gustavo Gile, 1972.

CANEVACCI, Massimo. Metrópole Comunicacional. In: Revista USP, São Paulo, n.63, p. 110-125, setembro/novembro. 2004.

ESTÚDIO SINESTESIA. Disponível em: <http://www.sinestesiaestudio.com/!fridafemini sta/c1qg5>. Acesso em 13 de fevereiro de 2016.

HOLLIS, Richard. Design gráfico. Uma história concisa. São Paulo: Martins Fontes, 2001.

MARGOLIN, Victor. Os dois Herbert: história, teoria e crítica no ensino de design em nível de doutorado. In: ARCOS. Design, cultura material e visualidade. Volume III. Rio de Janeiro: Contra Capa; Programa de Pós Graduação em Design / ESDI, 2000, p. 48-63.

McQUINSTON, Liz. Graphic Agitation. Social and political graphics since the sixties. London: Phaidon Press, 1993. 
Graphic Agitation 2. Social and political graphics in the digital age. London: Phaidon Press, 2004. 2015.

MEGGS, P. B. História do Design gráfico. São Paulo: Cosac Naify, 2009.

MENDES, C. F. As interferências da lei "cidade limpa" na paisagem urbana de São Paulo. In: II Colóquio internacional sobre comércio e cidade: uma relação de origem. São Paulo, 2008.

ROCHA, Ana Luiza Carvalho da; ECKERT, Cornelia. A retórica de um mito: "Brasil um país sem história". In: ROCHA, Ana Luiza Carvalho da; ECKERT, Cornelia. 0 tempo e a cidade. Porto Alegre: UFRGS Editora, 2005. p. 17-32.

SLATER, Don. Cultura do consumo e modernidade. São Paulo: Nobel, 2001. 